\title{
ÉTICA E COMUNICAÇÃO: O PROBLEMA DO VISÍVEL
}

Olgária Chain Féres Matos*

\section{RESUMO}

Trata-se de analisar a questão do crepúsculo da ética em um mundo dominado por mídias desinibidoras da violência, expondo espetáculos da crueldade tão impactantes quanto rapidamente esquecidos. Procura-se também refletir acerca do fenômeno de "desrealização" nos programas de extreme reality, cujas emissões inflacionam a mente com imagens que impedem de imaginar, de "esquematizar", para nos valermos da expressão da Terceira Crítica de Kant. Também é abordada a questão do fim da experiência do "escândalo" e do advento do "sensacionalismo", bem como do desaparecimento da intimidade no universo contemporâneo.

Palavras-chave: mídia, imaginação, ética, Kant, violência.

A preocupação com a ética nas democracias ocidentais contemporâneas revela-se por sua presença enfática nas reflexões filosóficas, nas instituições jurídicas, na bioética, nas ações humanitárias, na salvaguarda ao meio ambiente, na moralização dos negócios públicos e da política; comparece nos debates sobre a lei do aborto ou o assédio sexual, nas cruzadas antidrogas e no combate antitabagista; encontra-se nas campanhas de caridade e na mídia. Uma tal mobilização instala-se em um espaço deixado vazio pelo eclipsamento da tradição herdada da Grécia, Roma, Jerusalém: a

* Professora Titular no Departamento de Filosofia da Faculdade de Filosofia, Letras e Ciências Humanas da USP. [e-mail: olgaria@uol.com.br] 
phylia grega (laço afetivo das relações no espaço público), o direito civil romano que fazia de todos os homens do Império um cidadão, a herança judaico-cristã das máximas - "amarás ao próximo como a ti mesmo": "não matarás".

A palavra ethos aparece pela primeira vez em Homero, na Ilíada, significando "toca", "caverna", "morada". Antes de referirse ao caráter ético e à virtude, ethos é pertencimento numinoso, a partir do qual construir e habitar são tarefas que participam do sagrado, da indivisão antiga entre os homens, a natureza e os deuses. Na mais modesta casa, o homem imita a obra do deus, "cosmizando" o caos, santificando seu pequeno cosmos, fazendo-o semelhante ao divino. Permanecendo em um lugar determinado e determinável, a maneira de habitar é criação de valores, é ethos pelo qual a perfeição dos deuses prolonga-se e manifesta-se na ordem e na beleza do universo - o que se desenvolve na Grécia clássica, na busca da harmonia de uma cidade governada pela justiça, na elegância de uma vida de moderação e autarquia.

Na Ciência, o Sentido não é, como na ciência moderna, algo a ser construído, mas decifrado, revelado. Diferentemente da física moderna, a physis não é um reservatório de matérias e materiais que o homem submete por ser, na expressào de Descartes, "seu senhor e possuidor". Tudo o que o homem grego consegue saber, quer também viver: é a vida que serve ao pensamento e ao conhecimento - e não o contrário. E como o saber contemplativo e não a vita activa é o centro de suas especulações, ele "modera", pela razão $(\log o s)$, o desejo imoderado de conhecer. Do olhar do homem antigo ao moderno, J.-P. Vernant fala-nos, quando narra sua primeira viagem à Grécia, no início de seus estudos de helenista:

[...] navegava, à noite, de ilha em ilha; estendido no convés, olhava o céu por cima de mim, onde a Lua brilhava, luminoso rosto noturno que projetava seu claro reflexo, imóvel ou oscilando sobre a obscuridade do mar. Sentia-me deslumbrado, fascinado por aquele suave e estranho brilho que banhava as ondas adormecidas [...]. O que estou vendo é Selene, dizia para comigo, noturna, silenciosa, brilhante [...]. Muitos anos depois, ao ver na tela de meu televisor as imagens do primeiro astronauta lunar saltitando pesadamente 
com seu escafandro no espaço de uma desolada periferia, à impressão de sacrilégio que senti juntou-se o sentimento doloroso de uma ferida que não poderia ser curada: meu neto, que como todos viu essas imagens, já não será capaz de ver a Lua como eu a vi: com os olhos de um grego. A palavra Selene tornou-se uma referência meramente erudita: a Lua, tal como hoje surge no céu, não responde mais por esse nome. (VERNANT, 1993, p. 8)

A modernidade científica e tecnológica do "desencantamento" é a passagem da vita contemplativa à vita activa. Na modernidade, tudo é novo e se passa como previsto, o enigma da questão "por que existe o Ser e não antes o Nada?" é resolvido pela Ciência. Cada vez mais é nossa "vontade de potência" que cria o processo do mundo. Dizer que a modernidade se propôs a fazer a história é minimizar os acontecimentos: no mais profundo de si mesma, a modernidade quer fazer igualmente a natureza, forjando uma segunda physis na qual "nada é sem razão", pois o mundo é regido por um "princípio de razão suficiente". Assim a civilização deveria edificar-se em esperanças, segurança e instituições construídas segundo uma medida humana, no domínio das coisas para as quais a ciência nos faz competentes. No entanto, seu resultado é, para utilizar as palavras do filósofo alemão Sloterdjik, o "desespero metafísico".

A modernidade não se pergunta mais "para onde vamos", pelos fins últimos, pelo Sumo-Bem, valores da tradição que constituíram o humanismo ético moderno. Foi Cícero quem, no século II, criou a palavra humanitas para falar do povo romano que alcançou sua identidade através do cultivo e da filosofia grega, tornando-se, através deles, "fino, morigerado e humanus". Humanismo e valores morais reuniam "aquele misto de erudição e urbanidade que só podemos circunscrever", como observa Panofsky (1976, p. 20), "com a palavra já tão desacreditada, cultura". Sua formulação moderna é a de Kant: "todas as coisas que podem ser comparadas, podem ser trocadas e têm um preço. Aquelas que não podem ser comparadas não podem ser trocadas, não têm preço mas dignidade: o homem".

O economista inglês do século XIX, que lecionava "filosofia moral" em Cambridge, anotou algo que falta inteiramente hoje: "a 
palavra moral sense é de formação tardia e não pode ainda ser considerada como fazendo parte da língua inglesa". Como entender a expressão "senso moral"? Logo de início, poderíamos dizer que senso moral diferencia-se de "conhecimento moral". Nesse sentido, o senso moral seria "imediato", algo como um "tato moral", que significaria uma "faculdade" de distinguir o bem e o mal, sem ter necessidade para tanto de "raciocinar", "demonstrar". O senso moral de alguma forma pressuporia uma cultura moral, algo como um conhecimento nativo do bem e do mal que é assim introjetada: "se invoco em outrem, espero que ele julgue uma ação como eu o faria, graças a noções que somos supostos ter em comum um senso moral" (JoFFro, 2000, p. 57). Nas diversas épocas, a reflexão moral converge para o "governo de si", a "realização de si", para a autarquia, eudaimonia (a felicidade).

Pode-se dizer que nosso tempo é "pós-humanista". O par conceitual civilização-modernização diz respeito a uma cultura que assim pode ser caracterizada: cientificismo, isto é, aquiescência sem crítica à Ciência e suas práticas, sem se perguntar se são justas e desejáveis; adesào à idéia de progresso linear e contínuo, ao redimensionamento da razão em sentido tecnológico, abrangendo a economia e a política. A Razão não é mais considerada como livre faculdade de julgar, uma vez que todas as decisões econômico-políticas passam por soluções técnicas, com o que se abandona o ideal de reflexão, contemplação e autonomia do pensamento; modernização e modernidade dizem também respeito à sociedade de massa, do consumo, do espetáculo e à exaltação do mercado como sucedâneo da busca da felicidade. O que se entende por democracia de massa é, melhor dizendo, a universalização e "democratização" do consumo e dos desejos. A assimilaçào dos valores de consumo e a aquisição de bens materiais pela sociedade de massa substituem o "querer ser" pelo "querer ter" e é um poderoso redutor do pensamento crítico e se estabelece sob os auspícios da mídia que proscreve o esforço intelectual em nome da "facilidade". Com o estabelecimento das mídias - a radiodifusão em 1918, a televisão em 1945, a Internet, a biotecnologia -, a modalidade de convivência nas sociedades contemporâneas - o "pacto social" - antes regido pelo ideário 
humanista da confiança, do respeito, da responsabilidade -, isto é, por regras éticas, se desfaz.

O estágio atual da democracia midiática é incompatível com as normas e os valores que compõem o campo ético. Sua cultura é, para utilizarmos uma expressão do filósofo Sloterdjik, a do cinismo. Não o “cinismo antigo", o de Diógenes de Sínope (no século IV a.C.), que criticava as convenções sociais e era inseparável de uma moral altiva e de coerência ética, na recusa de todo o compromisso com os costumes de seu tempo. Cosmopolitas, os cínicos recusavam as fronteiras que separam e dividem homens e países, geram as guerras e os assassinatos. Guerras são a experiência do absurdo, uma vez que, pelas mesmas razões, ora os homens se entrematam, ora trocam medalhas. A ataraxia antiga - a renúncia aos desejos - levou a resultados diversos e opostos: na Antiguidade, a uma conduta de liberdade e autonomia individual; na modernidade, à apatia e à indiferença cúmplices da imoralidade deliberada e sem pudor.

Pode-se dizer que a comunicação midiática veicula e reforça a cultura de uma ética "indolor", a dos atuais tempos democráticos. Novos valores são transmitidos pelas mídias: fetichismo da juventude, fitness esportiva, cuidados com o corpo mas sem nenhum ideal do espírito. Esta "mobilizaçào total" da sociedade não mais pressupõe a moral como aperfeiçoamento e libertação individual e coletiva, mas o culto da eficácia e do sucesso. Vivemos uma época do pós-dever, sem obrigações ou sanções morais. Sociedades "pós-moralistas", elas celebram o puro presente, estimulando a gratificação imediata de desejos e pulsões - o que leva a interrogar a natureza mesma das sociedades contemporâneas, a mutação do caráter antropomórfico da sociedade, não mais centrada no homem, no indivíduo, no cidadão, em sua dignidade e liberdade, mas no consumo e no espetáculo.

De início, espetáculo e especulação têm raiz comum e dizem respeito a uma operação do olhar e da linguagem, consistem no ato de ver e dar-se a ver na esfera pública, na Ágora grega, onde indivíduos-cidadãos reuniam-se para dialogar e deliberar sobre a justa vida e o bem viver, procurando aquela sabedoria prática, a prudência, que provê a convivência em uma reciprocidade entre semelhantes e iguais. Operação do olhar e da linguagem, o espaço público é a esfera 
da visibilidade: a Grécia clássica - a da democracia ateniense inventou o teatro (a comédia, a tragédia), que, como observa Francis Wolff (2000, p. 11-14),

[...] permanece o arquétipo do espetáculo: tudo nele é visto por todos os lados, tudo está manifesto e reveste-se dos sinais exteriores da visibilidade; nele, o "pensamento" está totalmente voltado para o exterior, como o espaço do teatro reproduz-se no espaço da cidade. O orador da assembléia do povo que "aconselha sua cidade", atrai todos os olhares e brilha por sua doxa, no duplo sentido, do ponto de vista que ele tem sobre as coisas (suas opiniões) e do ponto de vista que se tem sobre ele (sua reputação, sua fama) [...]. A ética e a política constituem o cruzamento do "pensamento racional" e da pólis, têm um terreno tão amplo que seus limites se confundem com os limites do humano. A política não passa da realização de si, uma vez que o "si" é relação com o outro.

Já a "sociedade do espetáculo" contemporânea é a da visibilidade absoluta, mas em sentido perverso: é panóptica. O panópticon é um projeto carcerário cuja arquitetura foi concebida por Benthan no final do século XVIII. Nele há uma torre circular de vigilância central e uma construção em anel no exterior da torre, com aberturas que não permitem ver o que se passa dentro dela, pois biombos são dispostos entre as salas da torre. $\mathrm{O}$ vigia permanece invisível, mas seu olhar potencial grava-se na consciência do detento, modelando seu comportamento, obrigando-o a internalizar o controle de que é ou não é o objeto, uma vez que pode sempre estar sendo observado. Nesse dispositivo de visão há antes uma "sugestão de visão", o que enuncia uma nova e temível hegemonia dos sistemas de poder. Como Foucault analisa em Vigiar e punir, o indivíduo torna-se dócil, auto-regulado em sua submissão a um dispositivo de vigilância, por vezes real, por vezes virtual. No panopticon, cada prisioneiro aprende a desempenhar seu papel de prisioneiro diante de um olhar hipotético, e a desempenhá-lo bem. O prisioneiro aceita perder seu estatuto de sujeito agente, para interiorizar o controle, integrando-se a um "Todo" hipnótico. Esse panoptismo visa assegurar a visibilidade 
máxima do conjunto do corpo social ou de um único indivíduo, nada permanecendo na sombra. Nos anos do fascismo, Hermann Broch aproximou, pela primeira vez, o sentido desse panoptismo vinculado à gestão moderna das massas e o conceito de "pânico", retomado por Sloterdjik em seu livro A mobilização infinita.

A "civilização do pânico" vincula-se à passividade e à angústia existencial da perda do controle da natureza e do mundo e ao medo da destruição, relacionando-se ao "delírio" e não ao campo ético campo este da escolha, da consciência e da liberdade: "nunca uma época esteve tão disposta a suportar tudo e, ao mesmo tempo, a achar tudo tão intolerável" (AGAMBEN, 1995). A indiferença moral (desresponsabilização do indivíduo) e política (passividade) mantêm relações íntimas com os meios de comunicação de massa. A democracia - como esforço conjunto de ações e deliberações - é substituída pelo monopólio das informações disponíveis na mídia. O indivíduo "formado" por ela e ao qual se destina não tem pensamento próprio, o que o exime de responsabilidades e contribui para seu bemestar. Além disso, a mídia requer e "valoriza" um leitor ou espectador por sua incapacidade de concentração e, como escreve Entzenberger (1999, p. 49), "para eles, parece vantajoso não saber e não compreender o que acontece [...]. Eles são adaptáveis". A grande imprensa diária é colagem, montagem de "notícias": "a propaganda militar e o desodorante, a bomba nuclear e a fralda descartável, o asssassinato em massa e a ração para animais domésticos se equivalem" (p. 68). Nesse aspecto, a mídia televisiva é "mídia zero", exige um nada de atenção, um máximo de distração. Ela é a "aproximação tecnológica do nirvana. O televisor é uma máquina budista” (p. 81).

As mídias são desinibidoras da violência, do obsceno (o que não se mostra em cena), do cinismo. Razão pela qual Kierkegaard afirmou: "enquanto a imprensa diária existir, o cristianismo será uma impossibilidade". O modus operandi da mídia é incompatível com os valores éticos. Em nosso mundo, nada é obsceno porque tudo o é. Dramaturgia da permissividade, não há sequer o que transgredir. Timo Airaksinen, no ensaio "Escândalo e relíquia", observa o fim da experiência do escândalo no mundo contemporâneo; escândalos só podem existir se certos valores ou virtudes são violados. É possível 
guardar a memória de escândalos ocorridos, mas não serem criados novos. Nosso tempo ultrapassa qualquer escândalo ou talvez tudo seja tão escandaloso que essa noção não tem mais qualquer sentido. O que resulta, como escreve Timo, "que nada pode ser levado a sério, nem valores nem verdades". Para compreender melhor o que constituía uma "cultura do escândalo", é preciso inscrevê-lo em sua "racionalidade", em sua "inteligibilidade", em resumo, no espírito iluminista, aquele que acreditou que tudo pode ser explicado e compreendido. Tudo o que pode ser explicado não é escandaloso, pode ser no máximo uma "anomalia". O pensamento moderno iluminista acreditava que, tudo podendo ser explicado, pudesse ser regulado. Escândalos existiam quando uma explicação se rompia ou não conseguia se fazer atuante. Escândalos eram prova do limite e do fracasso do projeto iluminista: "um escândalo vive nas circunvizinhanças da virtude todas as vezes em que se desafia uma explicação em termos de valores ou virtude. Um escândalo é um impasse na compreensão moral. Um escândalo pode ocorrer no contexto ético do cristianismo, no romântico e no burguês Na tradição aristocrática e romântica, o escândalo se compreende diante dos valores da honra, do amor e da fidelidade. No contexto cristão, os valores da fé, do amor e da esperança. No burguês, os da castidade, da sobriedade, do trabalho e do sucesso. Enquanto ainda acreditávamos nesse conjunto de valores, escândalos eram possíveis. Talvez o escândalo maior seja o de não haver mais escândalos.

Citemos alguns exemplos no que diz respeito à cultura aristocrático-romântica. João faz uma promessa a Jacques. Se João não a cumpre, isso é um escândalo. Uma dama nobre apaixona-se pelo seu criado e se envolve com ele. Como o amor é uma relação honrada entre pessoas de honra e "sangue nobre", isso é um escândalo. Esse amor é escandaloso, como em $O$ amante de Lady Chatterley, de Lawrence. Valores e virtude não constituíam apenas valores e virtudes, mas consistiam também na auto-realização da consciência de um Sujeito. Lembre-se que no século VII, quando Pascal propõe a aposta matemática na existência de Deus, em um mundo de crença e de fervor religiosos, isso foi um escândalo. No nosso, em que "Deus morreu", crer ou não em Deus não constitui nenhum problema. Pode- 
se dizer que a cultura contemporânea é a do sensacionalismo, sensacionalismo que se caracteriza pela superficialidade e ausência de conteúdo consistente. Quando Mike Tyson arrancou um pedaço da orelha de Hollyfield, isso não foi um escândalo, mas sensacionalismo. Se continua a ver as lutas, a ouvir comentários infindáveis sobre isso, nada precisa deixar de ser mencionado, ao contrário, tudo deve ser dito. O mesmo pode ser dito de Bill Clinton e suas aventuras sexuais. O exibicionismo de nosso tempo encoraja o sensacionalismo, não condena escândalos. Escândalos supõem noções prescritivas e normativas para comunicar suas características que não podem ser mencionadas, se o for, a comunicação é imediatamente interrrompida, encerra-se qualquer discussão. Quanto ao sensacionalismo, ele constitui o elemento-chave da informação no mundo contemporâneo.

Sua contrapartida ética encontra-se, em uma perspectiva humanista renovada e renovadora, naquelas práticas existenciais e intelectuais que se contrapõem aos procedimentos da mídia: as artes. Suas "narrativas" - as da mídia, as das artes - não constituem dois discursos concorrentes, mas duas maneiras de viver e de comunicar, dois planos diversos de existência em uma cultura: a narração dirigese a uma comunidade, a informação visa a um mercado. A opinião pública midiatizada é tocada por imagens, impactos emocionais de acontecimentos, tão intensos quanto breves. Oscila-se entre a indignação e a compaixão, mas não se trata nunca de reflexão e compreensão. Razão pela qual Deleuze escreveu: "vejo no desenvolvimento fenomenal das imagens e das mídias o après coup do pacto rompido com a palavra. A desbelief como dizem os ingleses". A linguagem da mídia busca comunicar algo instantaneamente, como nos cartazes publicitários. Contra isso encontra-se a língua literária, só ela pode constituir um freio à instantaneidade das trocas econômicas. São necessários três segundos para transferir uma conta bancária, mas são necessários trinta anos para traduzir-se Borges. É esse "reatardamento" que permite captar o tempo longo da tradição - a tradição é um obstáculo à violência do mercado mundial. Que se recorde Heidegger quando traduziu o aforismo de Heráclito ethos anthrópo daímon (o homem habita na proximidade de Deus). Essas três palavras foram traduzidas em trinta páginas. Heidegger traduziu 
do grego interpretando-a, e essa interpretação é a melhor forma de tradução possível: "a filosofia", escreveu o poeta e tradutor Michel Deguy, "consiste em pensar em trinta páginas aquilo que foi dito em três palavras" (Cult, n. 52, nov. 2000, p. 9). A literatura de uma língua é a proteção dessa língua. Se o interesse pela literatura diminuir ou desaparecer é a própria língua que estará ameaçada de extinção.

O humanismo e a ética, diversamente da mídia, encontram-se, pois, indissoluvelmente ligados à alfabetização, à educação, à leitura. A educação, formadora do caráter, encontrava nela (na leitura) o procedimento por excelência nobre. Atividade paciente e concentrada é experiência que trabalha nossos medos e nossas esperanças e requer tempo, à distância do tempo acelerado, hegemônico no Ocidente, o tempo dito "real". Proust, em À sombra das raparigas em flor, narra como, progressivamente, foi-se constituindo para ele a sonata de Venteuil, cujos compassos acompanham toda a Recherche:

[...] esse tempo de que necessita um indivíduo para ingressar em uma obra profunda é como o resultado e símbolo dos anos e, por vezes, séculos que devem transcorrer até que o público possa apreciá-la verdadeiramente [...]. Foram os próprios quartetos de Beethoven que levaram cinqüenta anos para dar vida e número ao público de suas composições, realizando o que seria impossível encontrar quando a obra-prima apareceu, isto é, criaturas capazes de amá-la.

As obras de pensamento representam partes inteiras de uma vida e de toda uma existência construída de paradoxos, enganos e liberdade. É preciso gerações para recebê-las e interpretá-las - para decifrar a serenidade de Sócrates no momento de sua morte, os êxtases de Plotino, as noites atormentadas das Meditações metafísicas de Descartes. Uma vida examinada nas obras de cultura não pode ser regida pela temporalidade e pelos valores da mídia que impregnam a cultura e a educação. Todas as obras que se consideram universais no campo da cultura são o resultado de universos que, aos poucos, superando as leis do mundo comum e, sobretudo, a lógica do lucro, se foram consolidando. Dos pintores do Quattrocento - que precisavam lutar contra seus clientes para que suas criações deixassem de ser 
tratadas como mero produto, avaliadas pelo espaço da superfície pintada e pelo preço das tintas empregadas - até hoje, a cultura tem sido uma resistência para impedir que a lógica da compra e da venda comandasse os bens culturais. Reintroduzir o reino financeiro em universos que se foram constituindo contra ele é colocar em risco as mais altas realizações da humanidade em seus esforços humanizadores - a arte, a literatura, a ciência, a filosofia.

Nesse sentido, Burckhardt escreveu sobre os "grandes homens" e os bens culturais: grandes são Platão, Píndaro, Sófocles, Solon, Galileu, Michelângelo, Rafael, mas não os grandes navegadores, porque a América teria sido descoberta, mesmo se Colombo tivesse morrido recém-nascido. Mas a pintura "A Transfiguração" de Rafael não teria sido realizada se ele não o tivesse feito. Grandes são aqueles sem os quais o mundo seria incompleto. Humanismo, pois: a civilização dos costumes e o abrandamento das tendências destrutivas na sociedade e as boas leituras que conduzem à afabilidade, à amizade, à sociabilidade. O escritor Jean-Paul escreveu serem os livros cartas, decerto longas, que se escrevem aos amigos. São eles propiciadores de uma amizade realizada a distância por meio da escrita. Diferentemente das "amizades" da Internet, a cultura encontrada nas obras da literatura universal requisita o mundo letrado.

Sem a inscrição da filosofia grega em papiros transportáveis, as mensagens longínquas no tempo a que se chama tradição não teriam chegado até nós. Essa amizade dos grandes escritores com o público leitor de suas mensagens representa um caso de amor a distância. Poderíamos dizer que ao humanismo subjaz a crença em uma sociedade literária na qual se descobre, por intermédio das leituras canônicas, um amor comum pelos remetentes que o inspiraram. Só podemos, assim, compreender o ideário do humanismo moderno como tomada de partido de um conflito entre mídias desinibidoras que são, também, desumanizadoras. Que se pense nos entretenimentos desinibidores da mídia e seus filmes-catástrofe. E com isto estamos de volta aos romanos. O que os romanos do tempo de Cícero, os romanos cultos, denominavam com a palavra humanitas seria impensável sem a exigência de abster-se da cultura de massa e de seus teatros da crueldade. 
Tanto para a humanização quanto para a crueldade, os romanos nos legaram alguns exemplos, quando se substituiu o teatro trágico dos gregos e suas reflexões sobre a fragilidade da condição humana pelos anfiteatros de gladiadores. Cultura "desumanizadora", os romanos já haviam instituído a mais bem-sucedida rede de meios de comunicação de massa do mundo antigo, com açulamento de animais ferozes, seus combates de gladiadores até a morte e seus espetáculos de execuções públicas. Quanto ao humanismo, voltava-se para aquilo que Norbert Elias denominou a "civilização dos costumes", do processo civilizatório que poderia aqui ser compreendido segundo a idéía de influências "inibidoras" e "desinibidoras" da destrutividade social, dos conflitos entre os homens. Por isso, Sloterdjik chama a atenção para o humanismo antigo, dizendo que só o podemos compreender como uma tomada de partido de um conflito entre mídias, no caso a resistência do livro contra o anfiteatro, como oposição da leitura filsosófica humanizadora - provedora de paciência e criadora de consciência - contra as sensações impacientemente arrebatadoras dos estádios onde se instala a multidão. $O$ poder de sedução das imagens já fizera, na Antiguidade, Platão expulsar de sua República Ideal o artista para evitar a proliferação das imagens-simulacros, imagens-fantasmas; atraentes, há imagens que embaralham a visão e o pensamento, impossibilitando o exercício da faculdade de bem avaliar.

O embaralhamento da visão e da compreensão dá-se, hoje, na impossibilidade de discernir o real e o virtual. Foi este o caso quando dos ataques terroristas nos EUA. A TV francesa emitia as imagens com o letreiro: "isto não é uma ficção". Se a ficção se confunde com a realidade não é pelo fato de a realidade "imitar" a ficção, mas porque a linguagem televisiva é profundamente "realista": "realismo" reencenado como em "Linha direta", da Globo; pré-fabricado como "pegadinhas" do Faustão; realismo coreografado, como o do multishow ou realismo extremo como Extreme Reality (AXN): polícia real persegue um bandido real em carros reais por estradas reais, causando acidentes reais. Tudo se passa como se o realismo desse o sentimento de segurança graças ao qual sentimos a existência palpável e reconhecível das coisas, para que tudo não passe de imaginação ou 
delírio. Mas o realismo na forma de apresentar a realidade desfaz o efeito do real. Ao buscar ser realista, a imagem substitui o real. Depois do acontecido em NY, a TV passou a repetir a mesma imagem. Por excesso de realismo a imagem torna-se irreal. O sentimento do deinos, do terrífico na tragédia grega, e do unheimlich - o perturbante em Freud - associam-se: em ambos o sentimento de desrealização, de despersonalização. As imagens são delirantes, pois é próprio do delírio excluir a consciência, não se converter a explicações lógicas; o delírio não é reversível pela prova da experiência - e quando se vive de acordo com o delírio -, pelo pânico da perda do mundo e pela angústia do "fim", o delírio pode tornar-se uma ideologia de vida. O extremo realismo procura mostrar as coisas sem qualquer mediação teórica, isto é, sem nenhum exercício de pensamento, como se o existente fosse despojado de sua essência, a realidade destituída de sua idéia. O real, a pura existência imediata, é intransitivo, indubitável e "sem fundamento": "o puro existente é opaco, permanece fechado e recalcitrante ao pensamento, refratário e impermeável à razão" (PAREYSON, 1995, p. 404). Sendo assim, o real é algo inteiramente diverso do verdadeiro, pois o real é estranho à linguagem e à dimensão simbólica, é o que resiste à simbolização. O encontro com o real gera angústia e trauma, pois palavras e categorias se calam. O real é algo estranho ao significado. Sentimento de angústia, ameaça e perigo diante do "real" mudo, não permite o conhecimento do objeto que os provoca.

As imagens sem o "contexto" inviabilizam a compreensão do trauma, compreensão que poderia realizar o "trabalho do luto", luto que seria a possibilidade de um mundo ético. Se na tragédia antiga dava-se a catharsis, a tragédia moderna é sem "sublimação". Que se recorde a "recepção" da tragédia antiga: a construção e apresentação de sensações e emoções e o doloroso movimento de interiorizar conflitos e dores para, ao fim, liberar-se deles, vividos e compreendidos, isto é, transformados.

Sociedade pós-ética é a sociedade "pós-humanista", uma vez que nela os laços telecomunicativos entre os habitantes de uma sociedade de massa não se fazem pela leitura, como vimos, geradora, na tradição greco-latina, de amizade e sociabilidade. Criticar a cultura 
contemporânea requer incluir a crítica à mídia em nome do modelo amigável da sociedade literária. Assim como na Antiguidade romana o livro perdia sua luta contra os anfiteatros de gladiadores e todos os teatros da crueldade, hoje a educaçào formadora do espírito livre, de tolerância e compreensão do outro, está sendo vencida pelas forças indiretas das mídias padronizadoras do pensamento.

O ideário humanista separa o que as ideologias nivelam. Se a civilização ocidental contemporânea realiza, em permanência, cerimônias da destruição - que são ausência de realidade e reflexão, o ato de julgar lhe é, necessariamente, refratário, refratário a todo dogmatismo. Dogmatismo: conceber a política como hostilidade a quem pensa diferente: "[os verdadeiros humanistas] não fazem bons vencedores políticos pois são incapazes de aceitar superficialmente a morte do adversário" (CAMUs, 1981). O humanismo opõe-se a toda prática dogmática e da cultura do ressentimento e seu gosto por sacrifícios sangrentos. O ressentimento que leva às tiranias só conhece a intimidação. Camus caracteriza-o nas seguintes palavras: "o ressentimento deleita-se antecipadamente com uma dor que ele gostaria de ver sentida pelo objeto de seu rancor". Sua contrapartida, Camus a encontra na experiência da revolta: "a revolta, no interior de seu princípio, limita-se a recusar a humilhação, sem pedi-la para o outro. Aceita até a dor para si mesma, para que sua integridade seja respeitada" (1981, p. 30-31). Na contramão dessa cultura do ressentimento e da vingança, encontram-se o homem justo e a justiça, tal como Camus os encontra no Livro dos mortos:

[...] o egípcio justo era aquele que poderia poder dizer: "nunca causei medo a ninguém" para merecer perdão. Assim, jamais encontraremos nossos contemporâneos no dia do juízo final na fila dos bem-aventurados.

No reverso da cultura do ressentimento e da vingança e, à distância dela, o filósofo Levinas, por sua vez, refere-se à ética, valendo-se de um neologismo para significar a necessidade e a urgência de retorno às questões primeiras (à ética), à responsabilidade a priori que um tem com respeito ao Outro: excedência é o seu nome. Essa sensibilidade originária ao Outro requer que eu me ponha 
em seu lugar. Aqui, mesmo as palavras "tolerância" e "intolerância" já não fazem mais sentido, pois não se trata de política e de poder, do vencedor e do vencido. mas de ir além da guerra ou mesmo da paz política. Levinas considera uma outra figura da paz, a paz ética.

A humanidade - que, no passado, tinha sua maneira peculiar de apertar as mãos - acha-se extinta no mundo que se considera lógico, em uma época que faz questão de apresentar-se como o império da razão: "os homens podem hoje tudo dominar por si mesmos", escreveu Camus, "mas há algo que a maior parte não poderá jamais reencontrar que é a força do amor que lhe foi roubada". Nem valor de uso, nem valor de troca, mas valor de puro afeto é o da hospitalidade. Talvez os homens possam encontrá-la "quando souberem crer que nada está ao abrigo do acaso, quando deixarem de admirar a força, odiar os inimigos e desprezar os infelizes. Duvido que seja para já" (WeIL, 1941).

\section{ABSTRACT}

This paper examines the twlight of the ethics meaning in a world dominated by the media wich desinhibits violence and exposes cruelty as shocking as soon forgothen. It also proposes to think about the phenomenon of realitydeprivation in the extreme realism of "reality shows" news inflating the mind with images wich empeache imagination in the kantian sense of The Third critique. It`s about the end of the scandal experience, sensationalism advent and the intimacy desppearance in the contemporaneity.

Key-words: midia, imagination, ethic, Kant, violence

REFERÊNCIAS

AGAMBEN, G. Homo Sacer. Torino: Einaudi, 1995.

CAMUS, A. L'homme revolté. Paris: Gallimard, 1981.

ENZENBERGER, H. Mediocridade e loucura. São Paulo: Ática, 1999.

FOUCAULT, M. Surveiller et punir. Paris: Gallimard, 1985.

JOFFRO, L. La formation de la doctrine du sens moral: une histoire de la philosophie morale de Locke a Kant. Paris: PUF, 2000. 
KANT, E. Fundamentação à metafísica dos costumes. São Paulo: Abril Cultural, 1974. (Coleção Os Pensadores).

LEVINAS, E. Totalité et infini. Paris: Minuit, 1998.

PANOFSKY, E. O significado nas artes visuais. São Paulo: Perspectiva, 1976.

PAREYSON, L. Ontologia della libertà. Torino, 1995.

PROUST, M. À Sombra das raparigas em flor. Rio de Janeiro: Globo, v. 1, 1987.

SLOTERDJIK, P. La mobilisation infinie. Paris: Minuit, 1998.

VERNANT, J. P. O homem grego. Lisboa: Editorial Presença, 1993.

WEIL, S. La source grecque. Marseille: Cahiers du Sud, 1941.

WOLFF, F. Aristóteles e a política. São Paulo: Discurso Editorial, 2000.

ReCEBIDO EM 06/01/2003

Aprovado em 13/05/2003 